OPEN ACCESS

Check for updates

\title{
Excess deaths associated with covid-19 pandemic in 2020: age and sex disaggregated time series analysis in 29 high income countries
}

\author{
Nazrul Islam, ${ }^{1,2}$ Vladimir M Shkolnikov, ${ }^{3,4}$ Rolando J Acosta, ${ }^{5}$ Ilya Klimkin, ${ }^{4}$ Ichiro Kawachi, ${ }^{6}$ \\ Rafael A Irizarry, ${ }^{5,7}$ Gianfranco Alicandro, ${ }^{8}$ Kamlesh Khunti, ${ }^{9,10}$ Tom Yates, ${ }^{9,11}$ Dmitri A Jdanov, ${ }^{3,4}$ \\ Martin White, ${ }^{2}$ Sarah Lewington, ${ }^{1,12}$ Ben Lacey ${ }^{1}$
}

For numbered affiliations see end of the article.

Correspondence to: N Islam nazrul.islam@ndph.ox.ac.uk (ORCID 0000-0003-3982-4325)

Additional material is published online only. To view please visit the journal online.

Cite this as: $B M J$ 2021;373:n1137 http://dx.doi.org/10.1136/bmj.n1137

Accepted: 29 April 2021

\section{ABSTRACT}

OBJECTIVE

To estimate the direct and indirect effects of the covid-19 pandemic on mortality in 2020 in 29 high income countries with reliable and complete age and sex disaggregated mortality data.

DESIGN

Time series study of high income countries.

SETTING

Austria, Belgium, Czech Republic, Denmark, England and Wales, Estonia, Finland, France, Germany, Greece, Hungary, Israel, Italy, Latvia, Lithuania, the Netherlands, New Zealand, Northern Ireland, Norway, Poland, Portugal, Scotland, Slovakia, Slovenia, South Korea, Spain, Sweden, Switzerland, and United States. PARTICIPANTS

Mortality data from the Short-term Mortality Fluctuations data series of the Human Mortality Database for 2016-20, harmonised and disaggregated by age and sex.

INTERVENTIONS

Covid-19 pandemic and associated policy measures.

MAIN OUTCOME MEASURES

Weekly excess deaths (observed deaths versus expected deaths predicted by model) in 2020 , by sex and age (0-14, 15-64, 65-74, 75-84, and $\geq 85$ years), estimated using an over-dispersed Poisson regression

\section{WHAT IS ALREADY KNOWN ON THIS TOPIC}

Assessment of the full impact of the pandemic on mortality in different populations should include both its direct effect on deaths from covid-19 and its indirect effect on deaths from other diseases

This requires estimation of "excess death"-the difference between the number of deaths from all causes during the pandemic and the expected number of deaths given a historical baseline from recent years

Studies reporting on excess mortality have not accounted for temporal and seasonal trends, or differences in the age and sex composition, across the countries when estimating excess mortality

\section{WHAT THIS STUDY ADDS}

The five countries with the highest absolute number of excess deaths were the US, Italy, England and Wales, Spain, and Poland; New Zealand had lower overall mortality than expected

The highest excess death rates (per 100000 ) in men were in Lithuania, Poland, Spain, Hungary, and Italy; the highest rates in women were in Lithuania, Spain, Hungary, Slovenia, and Belgium

Accounting for difference in age, the excess death rates were much higher in men than women in almost all countries model that accounts for temporal trends and seasonal variability in mortality.

\section{RESULTS}

An estimated 979000 (95\% confidence interval 954000 to 1001000 ) excess deaths occurred in 2020 in the 29 high income countries analysed. All countries had excess deaths in 2020, except New Zealand, Norway, and Denmark. The five countries with the highest absolute number of excess deaths were the US ( 458000,454000 to 461000$)$, Italy (89100, 87500 to 90700$)$, England and Wales (85400, 83900 to 86800$)$, Spain $(84100,82800$ to $85300)$, and Poland $(60100,58800$ to 61300$)$. New Zealand had lower overall mortality than expected $(-2500,-2900$ to -2100$)$. In many countries, the estimated number of excess deaths substantially exceeded the number of reported deaths from covid-19. The highest excess death rates (per $100000)$ in men were in Lithuania $(285,259$ to 311$)$, Poland (191, 184 to 197), Spain $(179,174$ to 184$)$, Hungary $(174,161$ to 188$)$, and Italy $(168,163$ to 173); the highest rates in women were in Lithuania $(210,185$ to 234$)$, Spain $(180,175$ to 185$)$, Hungary $(169,156$ to 182$)$, Slovenia $(158,132$ to 184$)$, and Belgium (151, 141 to 162). Little evidence was found of subsequent compensatory reductions following excess mortality.

CONCLUSION

Approximately one million excess deaths occurred in 2020 in these 29 high income countries. Age standardised excess death rates were higher in men than women in almost all countries. Excess deaths substantially exceeded reported deaths from covid-19 in many countries, indicating that determining the full impact of the pandemic on mortality requires assessment of excess deaths. Many countries had lower deaths than expected in children $<15$ years. Sex inequality in mortality widened further in most countries in 2020.

\section{Introduction}

During the SARS-CoV-2 pandemic, national governments have reported the number of deaths from covid-19, often on a daily basis. However, widespread heterogeneity exists in the accuracy and completeness of reported deaths from covid-19 across countries and jurisdictions. ${ }^{12}$ Measures taken to handle the covid-19 pandemic have also varied substantially across countries. $^{1 \text { 3-8 }}$ Therefore, assessment of the full impact of the pandemic on mortality should include both the 
direct effect of the pandemic on deaths from covid-19 and the indirect effect of the pandemic on deaths from other causes, as might be expected from the disruption to health services or from wider economic and social changes. $^{\text {9-17 }}$

Assessing the overall impact of the pandemic on mortality requires measurement of "excess deaths," calculated as the difference between the number of deaths from all causes that occurred during the course of the pandemic and the expected number of deaths based on a historical baseline from recent years. ${ }^{18-21}$ Mortality below the expected levels is called "avoided mortality" or "mortality deficit," whereas "mortality displacement" (or "harvesting") is characterised by a period of excess deaths followed by a period of mortality deficit (see glossary in supplementary materials for more information). ${ }^{13} \quad{ }^{22}$ Mortality displacement indicates that people who have died during the course of an event (in this case, the covid-19 pandemic) would have died soon after in the absence of the event (that is, their death was brought forward by a short period). Previous studies have varied in their use of historical baselines to calculate excess deaths. Some have compared deaths during the pandemic with those reported in 2019 or with a simple average of the preceding few years. ${ }^{20}$ However, estimates of expected deaths should ideally account for recent temporal trends in mortality that are likely to have occurred in the absence of the pandemic. ${ }^{212324}$

Focusing on excess deaths from all causes also reduces the potential for misclassification of deaths from covid-19 and other causes, which facilitates comparisons between countries. ${ }^{18-21}$ The reliable ascertainment of deaths from covid-19 depends on widespread testing for covid-19 and on the methods used to assign cause of death, both of which vary between countries. ${ }^{12}$ In addition, as the case fatality from covid-19 is strongly related to age, comparisons between countries should account for this by stratifying or standardising excess deaths for age. ${ }^{25} 26$

We report the findings on excess deaths from the covid-19 pandemic in 29 countries after accounting for temporal trends and seasonal variations in mortality within countries, and for demographic differences between countries, to give age and sex specific excess mortality in each country during 2020.

\section{Methods}

\section{Study design}

We did a time series analysis of weekly mortality data collected from 29 member countries of the Organisation for Economic Cooperation and Development (OECD). Data for this study came from the Human Mortality Database. The database collates mortality and population data from authoritative national agencies and is maintained by the Department of Demography at the University of California, Berkeley, USA, and the Max Planck Institute for Demographic Research in Rostock, Germany. ${ }^{27}{ }^{28}$ Data are made available in a standardised format for each country, disaggregated by age and sex.
Since the start of the covid-19 pandemic, weekly national mortality data have been collected from many of the countries represented in the database, to support objective and comparable assessments of the scale of short term variations in mortality (Short-term Mortality Fluctuations data series). We used age and sex specific mortality data from this series. Further details on the sources of data and on the methods for collection and standardisation of data for the series are available in the supplementary table S1. ${ }^{29} 30$

Weekly mortality data were available for most OECD countries in the database for the period 2016-19, but delays in registration of vital events meant that weekly mortality data for some countries were available for only part of 2020. We restricted our analyses to 29 countries with complete weekly data in 2020 (52 weeks). Weekly mortality data were available by sex and by 5 year age groups $(0-4,5-9,10-14,85-89, \geq 90$ years) in 23 countries and by sex and broad age groups (0-14, 15 $64,65-74,75-84$, and $\geq 85$ years) for the remaining six countries (England and Wales (combined), Germany, Israel, South Korea, New Zealand, and the US).

\section{Statistical analysis}

For each country, we compared the age and sex specific number of deaths in each week in 2020 ("observed weekly deaths") with the age and sex specific number of expected deaths in each week given historical trends, to estimate the weekly number of excess deaths. We estimated weekly expected deaths by using an over-dispersed Poisson model that accounts for temporal trends and seasonal and natural variability in mortality. ${ }^{23}$ The model has been validated in simulation and when using historical data. ${ }^{23}$

For each age and sex specific group in a given country, the model used mortality data for 2016-19 to estimate the expected number of deaths in each group for each week of 2020. To ameliorate the influence of past major events on these estimates, past periods (2016-19) with atypical mortality (for example, heat waves, influenza outbreak) were excluded from the model (supplementary table S2).

Specifically, let $\mathrm{Y}_{\mathrm{s}, \mathrm{c}, \mathrm{a}}(\mathrm{t})$ be the number of deaths at week (t) for individuals of sex (s), in country (c), and age group (a). Note that (s) represents either female or male, (c) can be any of the 29 OECD countries, and (a) takes on any of the aforementioned age groups. Assuming that $\mathrm{Y}_{\mathrm{s}, \mathrm{c}, \mathrm{a}}(\mathrm{t}) \sim \operatorname{Poisson}\left(\mu_{\mathrm{s}, \mathrm{c}, \mathrm{a}}(\mathrm{t})\right)$, our mean model is:

- $\quad \mu_{s, c, a}(t)=N_{s, c, a}(t) \exp \left\{\beta t+g_{s, c, a}\left(w_{t}\right)\right\}$ for $t \in I_{c}(1)$

The expected number of deaths at week ( $t$ ) for individuals of sex (s), in country (c), and age group (a) is represented with $\mu_{\mathrm{s}, \mathrm{c}, \mathrm{a}}(\mathrm{t}) ; \mathrm{N}_{\mathrm{s}, \mathrm{c}, \mathrm{a}}(\mathrm{t})$ is an offset that accounts for the population size; $\beta$ represents a linear effect of time that accounts for slow moving changes in mortality; $g_{s, c, a}\left(w_{t}\right)$ is a function that accounts for seasonal trends, where $w_{t} \in\{1,52\}$ represents a week of the year; and ( $\left.I_{c}\right)$ is a country specific training interval that is used to fit the model. For the smooth estimates of percentage change from average, let ( $t$ ') be a week in 2020; then: 


$$
\text { - } \quad \lambda_{\mathrm{s}, \mathrm{c}, \mathrm{a}}\left(\mathrm{t}^{\prime}\right)=\mathrm{\mu}_{\mathrm{s}, \mathrm{c}, \mathrm{a}}^{\wedge}\left(\mathrm{t}^{\prime}\right) \exp \left\{\mathrm{f}_{\mathrm{s}, \mathrm{c}, \mathrm{a}}\left(\mathrm{t}^{\prime}\right)\right\}(2)
$$

In model (2), $\lambda_{\mathrm{s}, \mathrm{c}, \mathrm{a}}\left(\mathrm{t}^{\prime}\right)$ represents the average number of observed deaths at week ( $\mathrm{t}$ ') for individuals of sex (s), in country (c), and age group (a). The number of deaths at week (t') in the counterfactual scenario of no pandemic is represented with $\mu^{\wedge}{ }_{s, c, a}\left(t^{\prime}\right)$ and it is used as an offset. Lastly, the function $\mathrm{f}_{\mathrm{s}, \mathrm{c}, \mathrm{a}}\left(\mathrm{t}^{\prime}\right)$ is a natural cubic spline with 12 internal knots. It follows that $\gamma^{\wedge}{ }_{s, c, a}\left(t^{\prime}\right)=\lambda \wedge_{s, c, a}\left(t^{\prime}\right) / \mu^{\wedge}{ }_{s, c, a}\left(t^{\prime}\right)-1$ represents a smooth estimate of percentage change from average at t'. We used the excessmort $\mathrm{R}$ package to fit our modelling scheme and provide a detailed description of the model in the supplementary methods.

We report the excess deaths and excess death rates in each country overall, by sex, and by age. To avoid a false sense of precision, ${ }^{21}$ numbers $<1000$ are rounded to the nearest ten, numbers between 1000 and $<100000$ are rounded to the nearest hundred, and those $\geq 100000$ are rounded to the nearest thousand. To facilitate the comparison of excess deaths between countries, the age and sex specific excess death rates in each country for 2020 were directly standardised to the 2013 European standard population to calculate the age standardised excess death rate in each country in males and females. ${ }^{31}$ We produced age standardised rates by using 5 year age groups for 19 countries but broad age groups (0-14, $15-64,65-74,75-84$, and $\geq 85$ years) for the remaining countries for which either data by 5 year age groups were not available or the weekly age and sex specific death counts were too small (such as in Estonia, Lithuania, Northern Ireland, and Norway). Rates in the broad age groups were adjusted, using methods developed by the Max Planck Institute for Demographic Research on data from the core Human Mortality Database, to those that would be expected given the age distribution of the standard population; they were thus comparable to rates calculated using 5 year age groups. ${ }^{32}$

We also compared the overall number of estimated excess deaths with the reported number of deaths from covid-19 in each country (source: covid-19 time series data collated by Johns Hopkins University Center for Systems Science and Engineering, available at https://github.com/datasets/covid-19/tree/main/ data). We used RStudio (version 1.4.1103) and Stata SE (v.15.1) for all statistical analyses. All data used in this analysis are fully anonymised and aggregated without any identifiable information.

\section{Patient and public involvement}

The rapid nature of this research project in the context of the ongoing covid-19 pandemic meant that participants were not involved in the development of the research question or the outcome measures, or in the design or implementation of the study; neither were participants asked to advise on the interpretation or writing of the manuscript. However, the findings will be widely disseminated to the public through official channels (press release, blogs, institutional websites, and repositories), personal communications, and social communication tools.

\section{Results}

\section{Excess deaths}

Table 1 shows the estimated number of excess deaths in 2020 for the 29 countries included in the analysis, overall and separately for men and women. All countries had excess deaths for 2020, except Norway and Denmark, for which we found no evidence of a difference between the observed and expected number of deaths, and New Zealand, for which we found evidence of fewer observed than expected deaths. Overall, we estimated that about one million ( 979000 , $95 \%$ confidence interval 954000 to 1001000 ) excess deaths occurred in the 29 countries analysed. The five countries with the highest absolute number of excess deaths were the US (458000, 454000 to 461000), Italy (89100, 87500 to 90700), England and Wales (85400, 83900 to 86800$)$, Spain $(84100,82800$ to 85300$)$, and Poland (60100, 58800 to 61300 ), whereas New Zealand had lower overall mortality than expected (-2500, -2900 to -2100). In most countries, the number of excess deaths was somewhat higher in men than in women.

The estimated number of excess deaths by age groups in men and women are available in supplementary table S3. Observed deaths in children $<15$ years were similar to the expected levels in most countries and lower than expected in some countries (for example, England and Wales, France, Israel, Italy, New Zealand, South Korea, and the US). The total number of excess deaths was largely concentrated among people aged $\geq 75$ years, followed by people aged $65-74$ years. Excess deaths in people aged 15-64 years were generally lower than in the older age groups with the exception of the US, where the total number of excess deaths was approximately 131000 in people aged 15-64 years (91500 (90200 to 92 800) in men and 39500 (38500 to 40500$)$ in women), higher than those estimated among people aged 65-74 and 75-84 years. New Zealand had lower than expected deaths across all the age groups.

The distribution of excess deaths over time varied by country. Figure 1 shows the estimated monthly (aggregated from the weekly estimates) excess deaths (per 100000 population) in 2020 for men and women, and figure 2 shows the percentage deviation from the expected deaths across weeks of 2020. Some countries did not see major increases in excess deaths at any point during 2020, including Denmark, Norway, South Korea, and New Zealand. Other countries reported one or more major waves of excess deaths, after which excess mortality fell to lower levels.

Consistent with the timing of known peaks of covid-19 infection, many countries had major waves of excess deaths in the northern hemisphere spring (March-May) and in autumn-winter (OctoberDecember). In spring, the level of excess deaths was particularly high (with some weeks of $>50 \%$ excess deaths) in Italy, Spain, England and Wales, Scotland, Northern Ireland, Belgium, and the Netherlands. In autumn-winter, levels of excess deaths were particularly high in Austria, Belgium, Czech Republic, 


\begin{tabular}{|c|c|c|c|}
\hline Country & Total No $(95 \% \mathrm{Cl})$ & No $(95 \% \mathrm{Cl})$ male & No $(95 \% \mathrm{Cl})$ female \\
\hline United States & $458000(454000$ to 461000$)$ & 245000 (243000 to 247000$)$ & $213000(210000$ to 215000$)$ \\
\hline Italy & $89100(87500$ to 90700$)$ & $49000(47900$ to 50000$)$ & $40200(39000$ to 41300$)$ \\
\hline England and Wales & $85400(83900$ to 86800$)$ & $45000(44000$ to 46000$)$ & 40400 (39400 to 41400$)$ \\
\hline Spain & $84100(82800$ to 85300$)$ & $41100(40200$ to 42000$)$ & $43000(42100$ to 43800$)$ \\
\hline Poland & $60100(58800$ to 61300$)$ & $35400(34500$ to 36300$)$ & $24700(23800$ to 25600$)$ \\
\hline France & $43500(42000$ to 45000$)$ & 24600 (23500 to 25700$)$ & $18900(17800$ to 20000$)$ \\
\hline Germany & 25900 (24000 to 27800$)$ & $17700(16400$ to 19000$)$ & $8200(6900$ to 9600$)$ \\
\hline Belgium & $17900(17200$ to 18500$)$ & 9000 (8600 to 9500$)$ & 8800 (8400 to 9300$)$ \\
\hline Hungary & 16600 (15900 to 17300$)$ & $8100(7600$ to 8500$)$ & $8500(8000$ to 9000$)$ \\
\hline Netherlands & $15300(14600$ to 16100$)$ & 8800 (8200 to 9300$)$ & $6500(6000$ to 7100$)$ \\
\hline Czech Republic & $14400(13700$ to 15000$)$ & 8000 (7500 to 8500$)$ & $6400(5900$ to 6900$)$ \\
\hline Sweden & $9300(8700$ to 9800$)$ & $5100(4700$ to 5500$)$ & $4100(3700$ to 4500$)$ \\
\hline Portugal & 8500 (7800 to 9100) & 4000 (3500 to 4500) & $4500(4000$ to 5000$)$ \\
\hline Greece & 7700 (7000 to 8300$)$ & $3500(3100$ to 4000$)$ & 4100 (3600 to 4600$)$ \\
\hline Austria & 6800 (6200 to 7300) & 3800 (3400 to 4200) & 2900 (2500 to 3300) \\
\hline Scotland & 6800 (6400 to 7300$)$ & $3900(3600$ to 4200$)$ & 2900 (2600 to 3300) \\
\hline Switzerland & 6800 (6300 to 7300$)$ & 4000 (3700 to 4400) & 2800 (2400 to 3200) \\
\hline Lithuania & 6800 (6500 to 7200$)$ & 3700 (3500 to 4000$)$ & 3100 (2800 to 3400$)$ \\
\hline Slovakia & 4400 (4000 to 4900) & 2300 (2000 to 2700$)$ & 2100 (1800 to 2400$)$ \\
\hline South Korea & 4000 (2900 to 5000) & 1800 (1000 to 2600) & 2200 (1400 to 2900) \\
\hline Slovenia & $3200(3000$ to 3500$)$ & $1600(1400$ to 1800$)$ & $1600(1400$ to 1800$)$ \\
\hline Northern Ireland & $2200(1900$ to 2400$)$ & 1000 (860 to 1200$)$ & $1100(980$ to 1300$)$ \\
\hline Israel & 2000 (1600 to 2400$)$ & 1300 (1000 to 1600$)$ & 690 (400 to 990$)$ \\
\hline Finland & 1000 (550 to 1500$)$ & $690(360$ to 1000$)$ & $320(0$ to 640$)$ \\
\hline Latvia & 820 (490 to 1100$)$ & $270(50$ to 490$)$ & 550 (310 to 790$)$ \\
\hline Estonia & $670(430$ to 910$)$ & $330(160$ to 490$)$ & $340(170$ to 520$)$ \\
\hline Norway & $-70(-470$ to 320$)$ & $100(-180$ to 370$)$ & $-170(-450$ to 110$)$ \\
\hline Denmark & $-160(-610$ to 300$)$ & $-40(-360$ to 290$)$ & $-120(-440$ to 200$)$ \\
\hline New Zealand & $-2500(-2900$ to -2100$)$ & $-1200(-1500$ to -970$)$ & $-1300(-1500$ to -1000$)$ \\
\hline
\end{tabular}

Hungary, Italy, Lithuania, Poland, Slovakia, Slovenia, and Switzerland. Within countries, we found little evidence of a difference between men and women in trends over time in the proportional increases in excess deaths in 2020.

In some countries, during some periods of the year, the observed number of deaths fell below the expected number of deaths, most notably in New Zealand in the middle of the year. Detailed age and sex specific estimated number of excess deaths and percentage deviation from expected deaths over time are provided in supplementary figure S1 (A-E) and supplementary figure S2 (A-E), respectively. Although excess mortality was higher in the older age groups in most of the countries, the observed mortality was lower than expected in children $<15$ years in many countries.

\section{Crude and age standardised excess death rates}

Figure 3 shows the age specific excess death rates (per 100000) in each country, separately in men and women. The excess death rate increased exponentially with age in both sexes, except in those countries with no evidence of excess deaths, for which we observed a reduction in excess death rates at older ages; a particularly marked reduction in excess death rates occurred in New Zealand at ages $\geq 65$ years. In most countries, age specific excess death rates were higher in men than in women, and the absolute difference in rates between the sexes tended to increase with age. However, in the
US, in contrast to other countries, the excess death rate (per 100 000) was higher among women (1899, 1855 to 1943$)$ than men $(1719,1653$ to 1784$)$ at ages $\geq 85$ years.

Figure 4 shows the crude and age standardised excess death rates in men and women. The highest crude excess death rates (per 100000) in men were in Lithuania (285, 259 to 311), Poland (191, 184 to 197), Spain $(179,174$ to 184$)$, Hungary $(174,161$ to 188$)$, and Italy $(168,163$ to 173$)$; the highest rates in women were in Lithuania (210, 185 to 234), Spain (180, 175 to 185$)$, Hungary $(169,156$ to 182 ), Slovenia (158, 132 to 184 ), and Belgium (151, 141 to 162). Although we found little evidence of differences between men and women in the crude excess death rates in 2020, almost all countries with excess deaths had higher age standardised rates for men than women (fig 4). The age standardised rates also varied substantially within men and women across the countries analysed. The highest age standardised excess death rates (per 100000) in men were in Lithuania (360, 324 to 396), Poland (298, 289 to 307), Hungary $(235,217$ to 254), Slovenia (222, 189 to 256), and the Czech Republic (211, 194 to 228); the highest age standardised rates in women were in Lithuania (152, 134 to 171), Hungary (144, 133 to 156$)$, the US (131, 129 to 133$)$, Spain (125, 121 to 129), and Northern Ireland (121, 97 to 146). The lowest age standardised excess mortality rates for both men and women were in New Zealand, Denmark, Norway, South Korea, and Finland. 

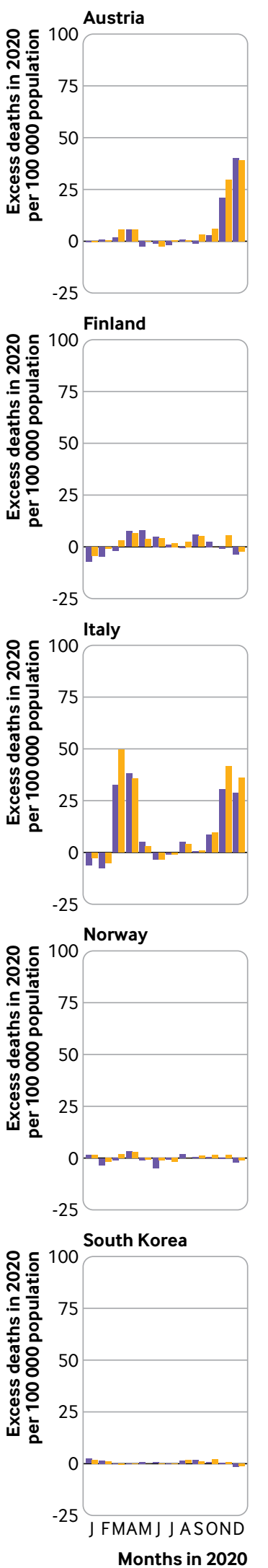
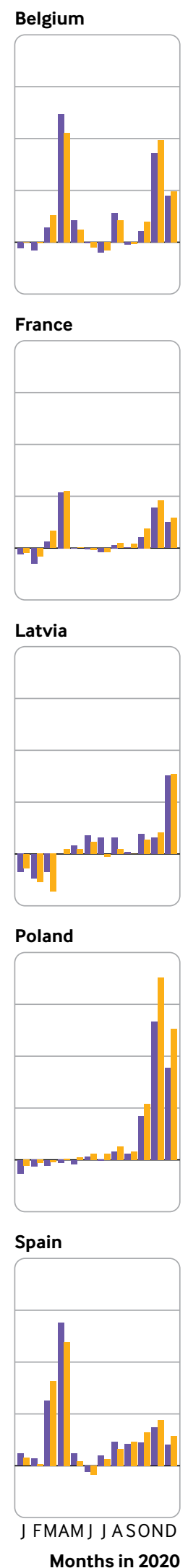
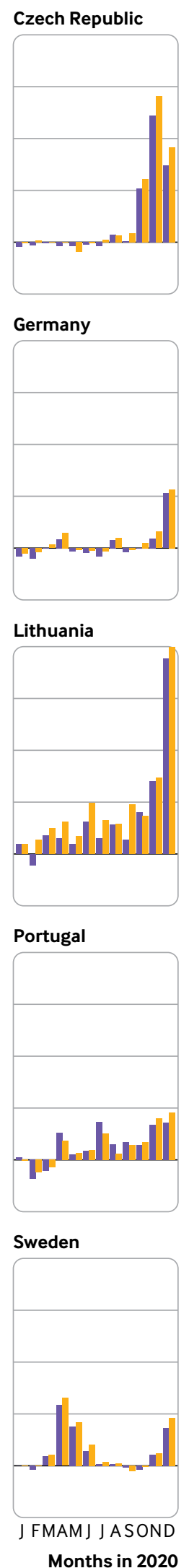
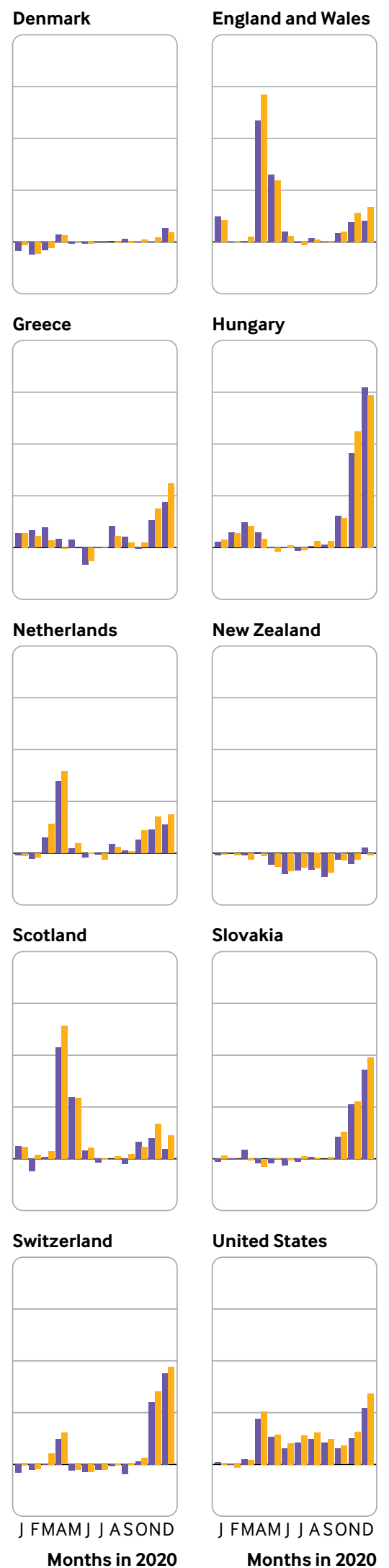

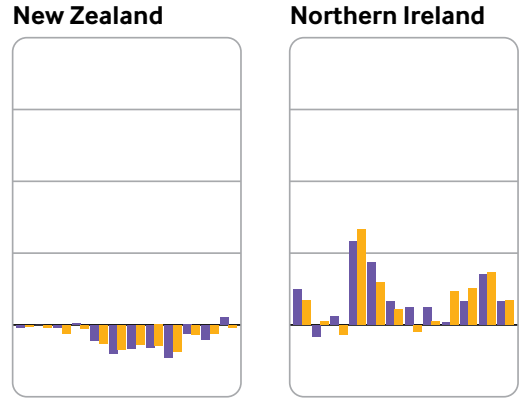

Slovakia
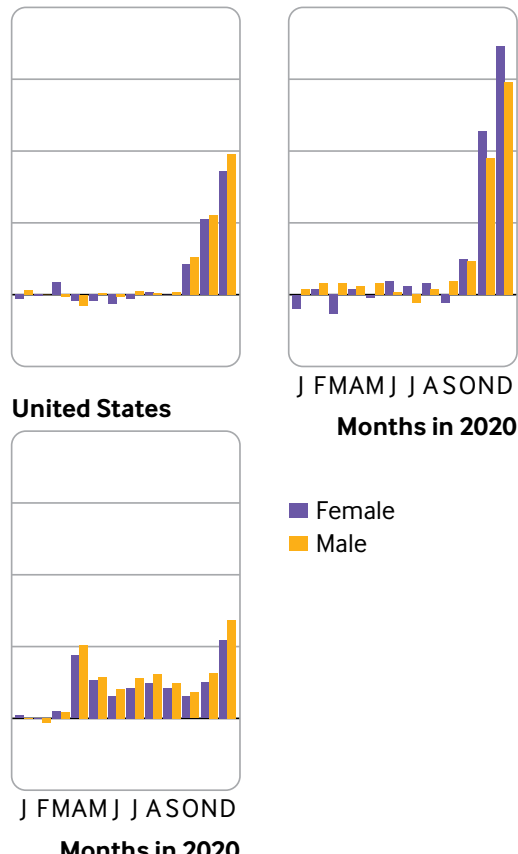
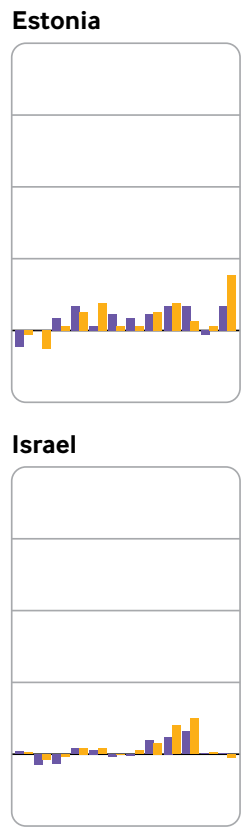

Slovenia

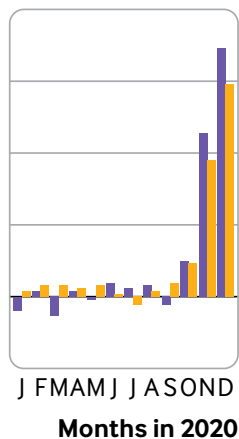

- Female

- Male

Fig 1 | Monthly excess deaths (per 100000) in 29 high income countries in 2020, all ages, by sex. Excess deaths in 2020 were calculated as difference in observed deaths and expected deaths predicted using over-dispersed Poisson model that accounts for temporal trends and seasonal and natural variability. Estimated excess deaths for each week of 2020 were aggregated into months. Data: Short-term Mortality Fluctuations data series of Human Mortality Database 

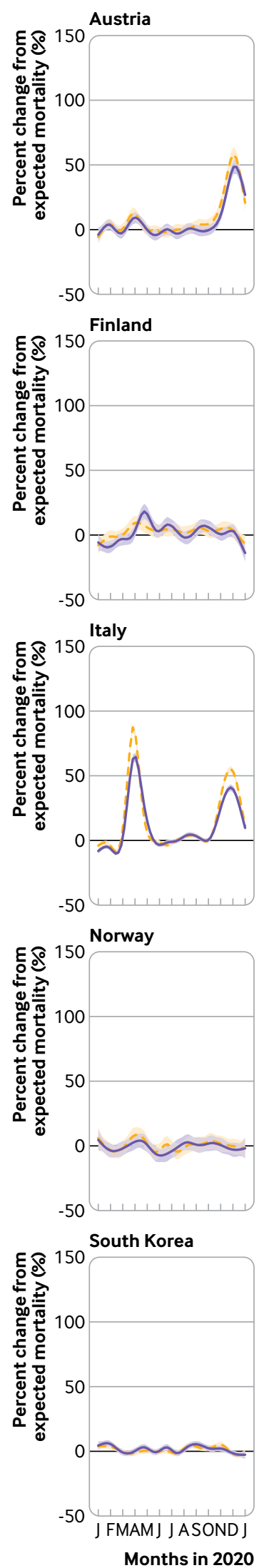

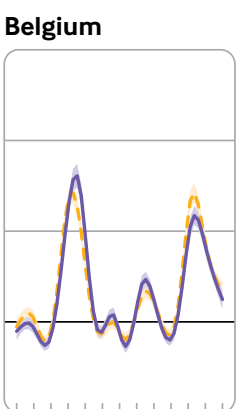

France

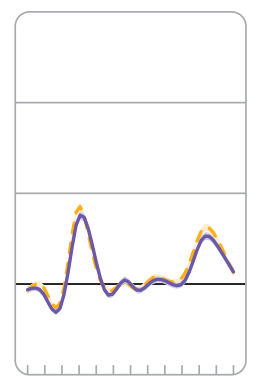

Latvia
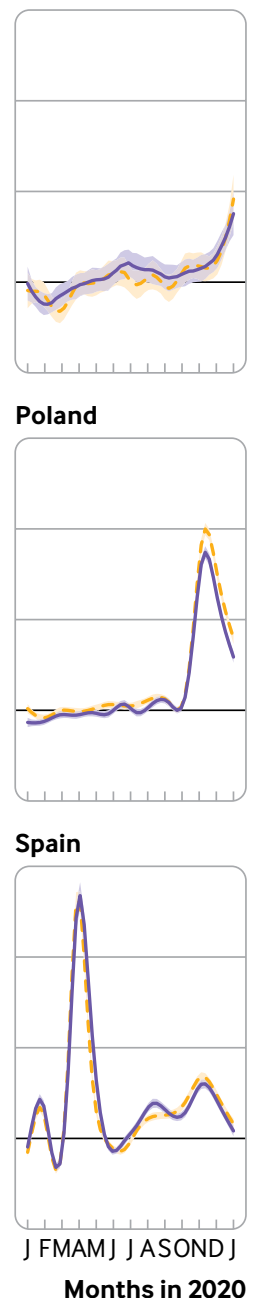

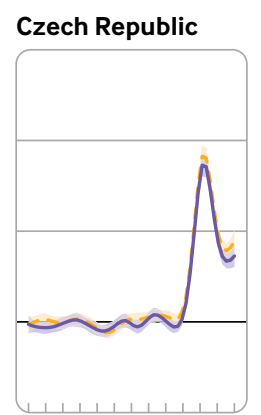

Germany

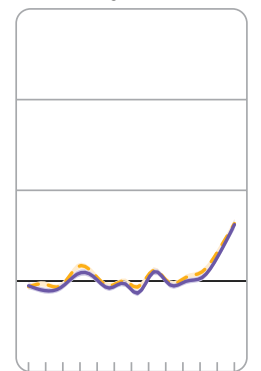

Lithuania
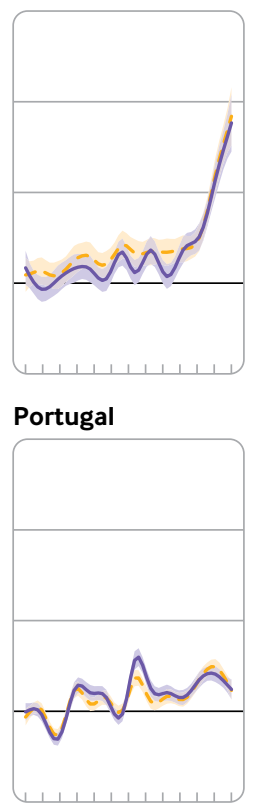

\section{Sweden}

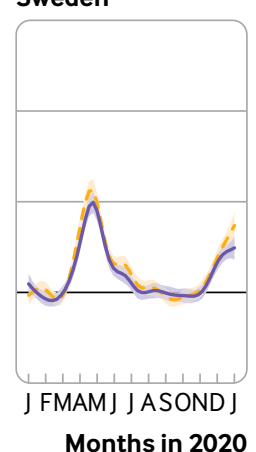

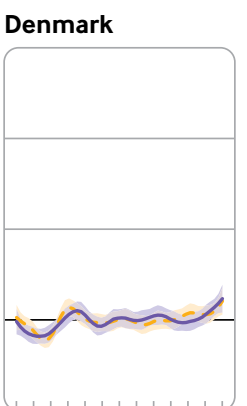
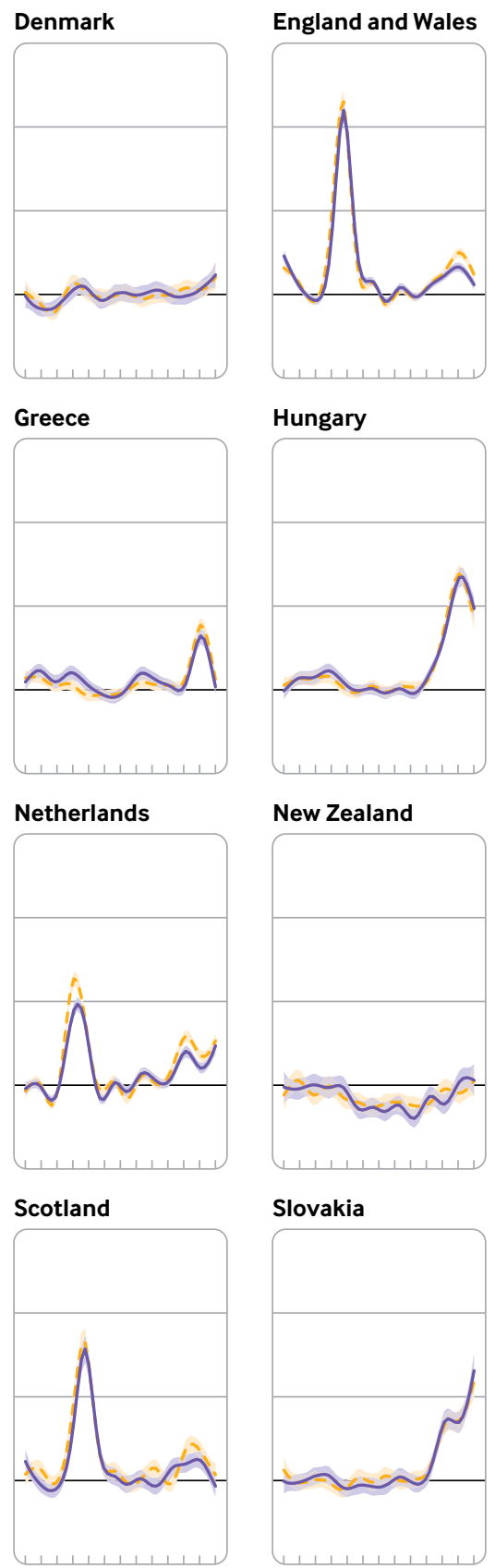

\section{Switzerland}

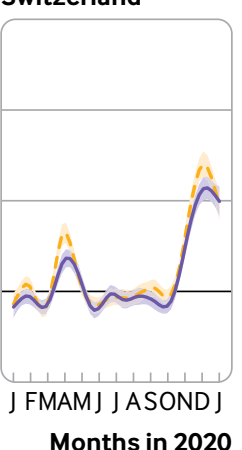

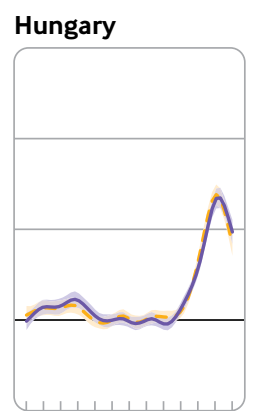
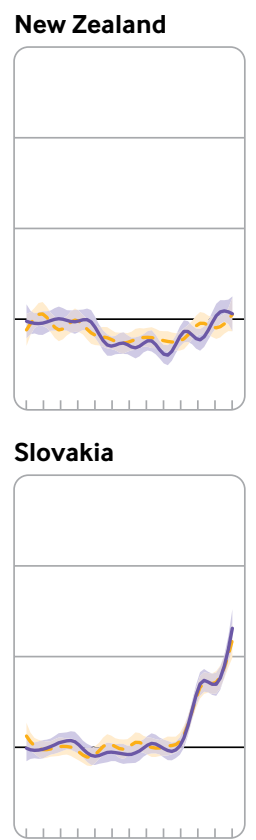

\section{United States}

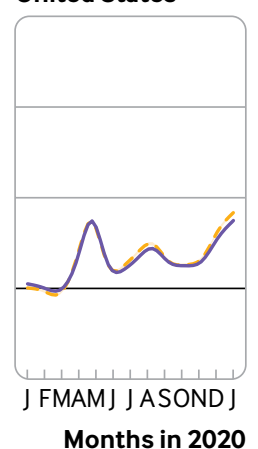

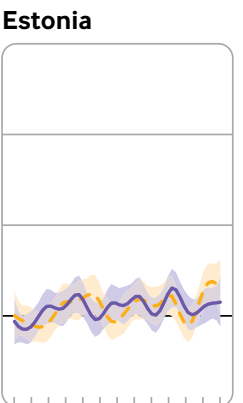

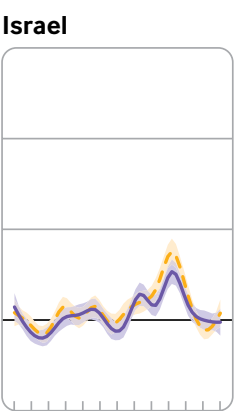

\section{Northern Ireland}

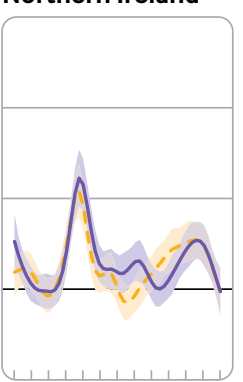

Slovenia

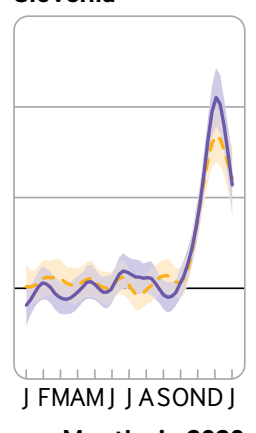

Months in 2020

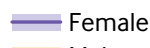

- - Male

Fig 2 | Weekly percentage deviation from expected deaths in 29 countries in 2020, all ages, by sex. Weekly percentage deviation of observed deaths versus expected deaths predicted using over-dispersed Poisson model that accounts for temporal trends and seasonal and natural variability. Percentage changes from mean during study period were modelled using smooth function of time. Data: Short-term Mortality Fluctuations data series of Human Mortality Database 

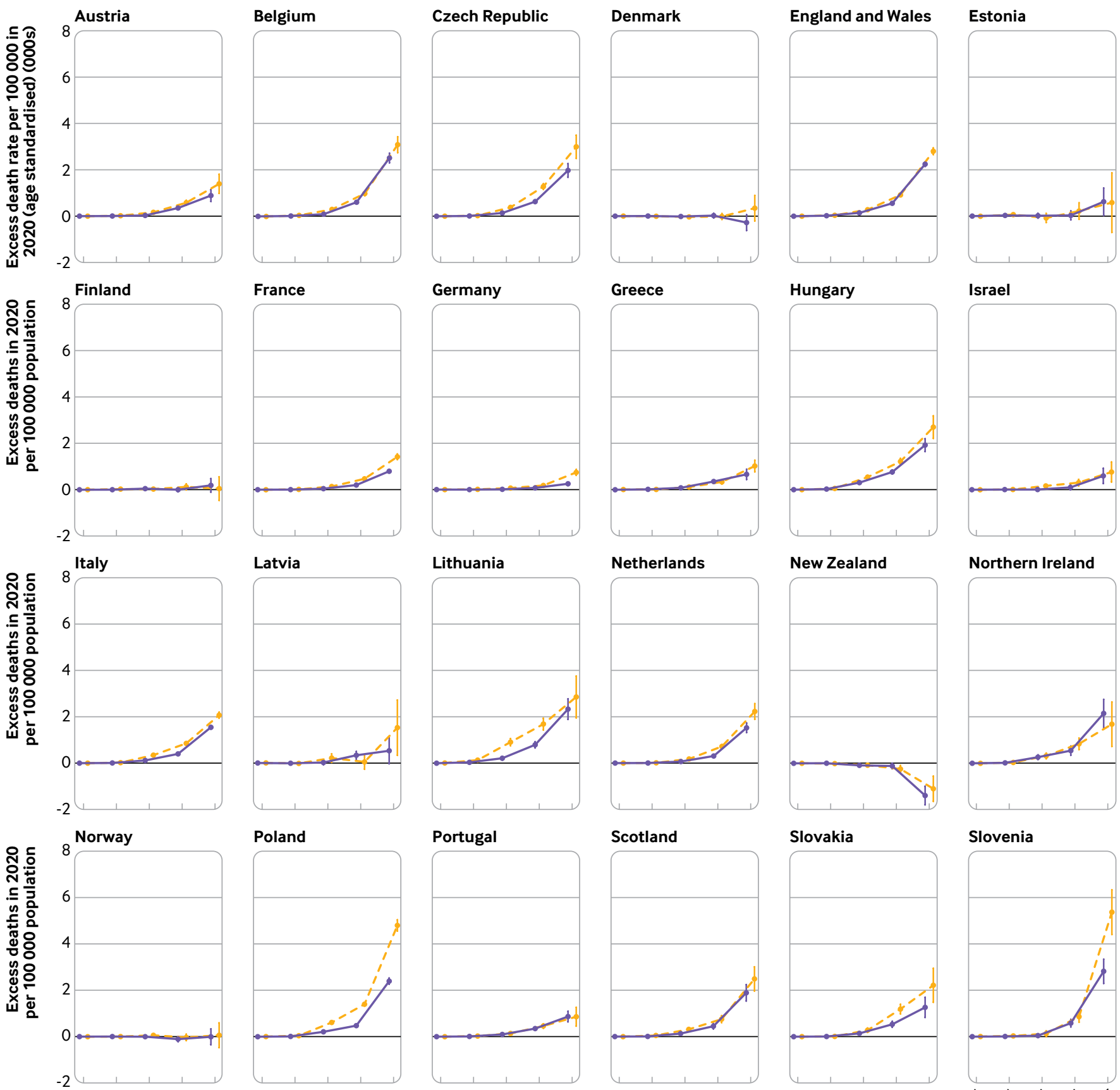

Poland

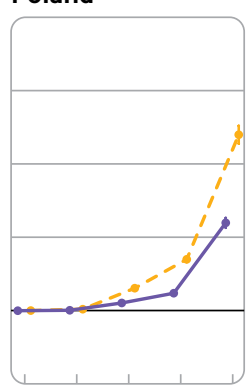

Portugal

Scotland

Slovakia

Northern Ireland
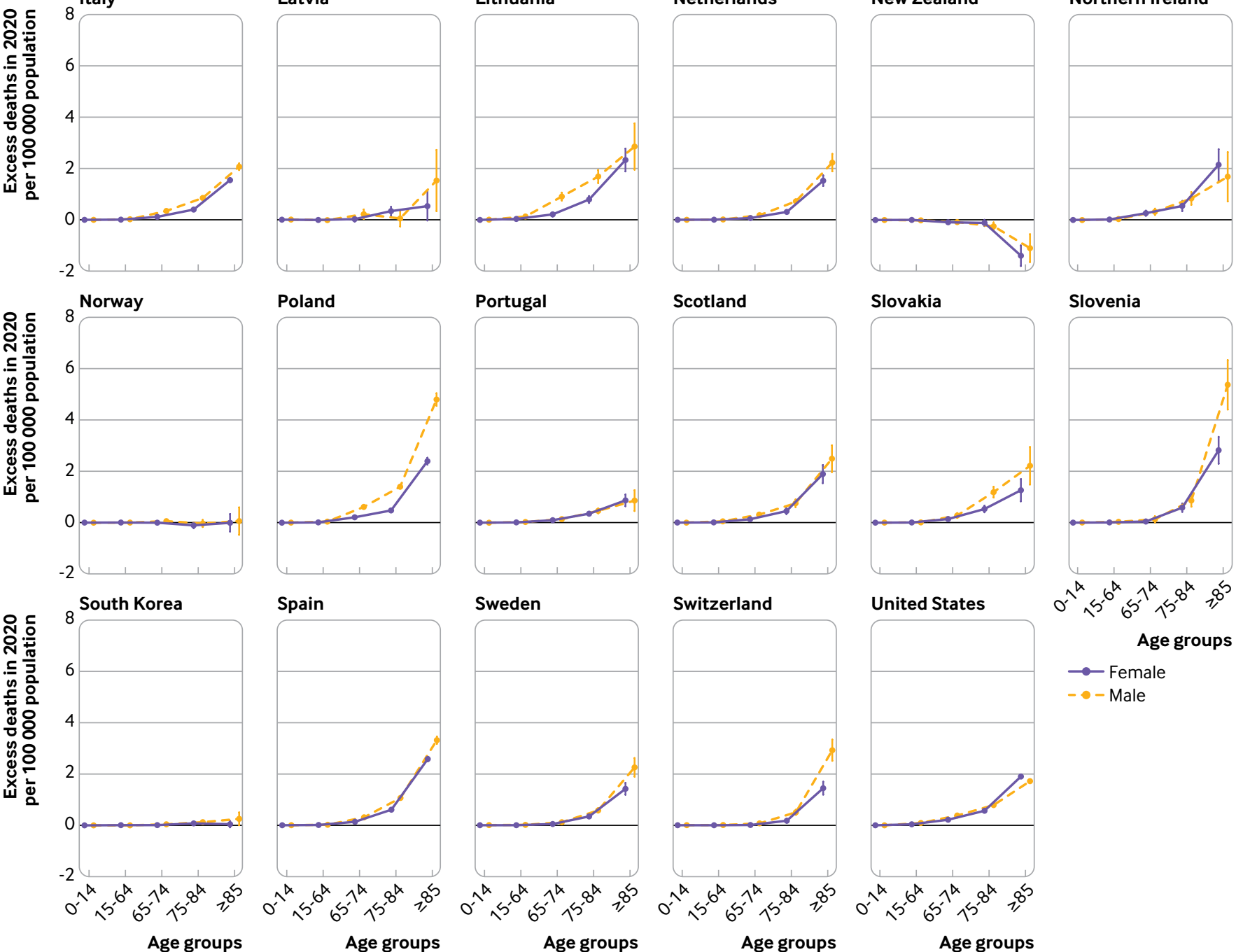

Slovenia
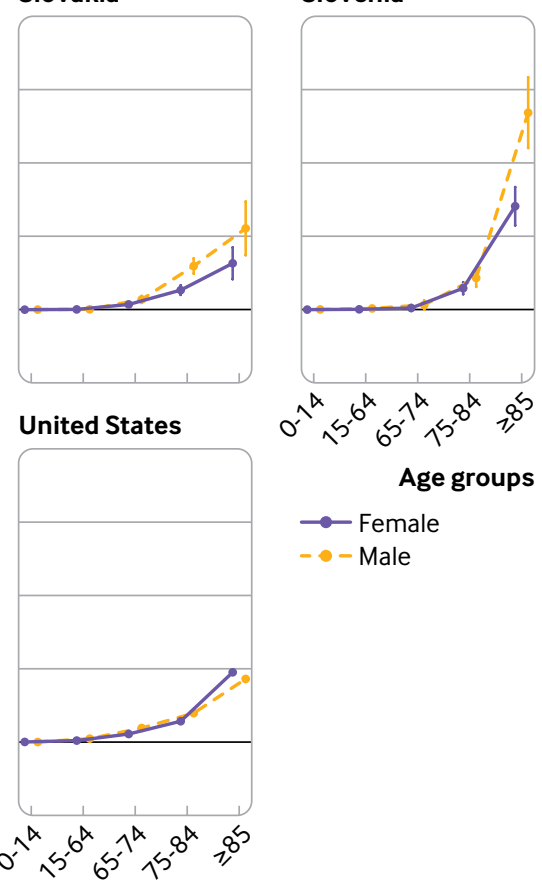

- Male

Fig 3 | Excess death rates in 29 high income countries in 2020, by sex and age. Excess death rate (per 100000) in 2020 was calculated as difference in observed deaths and expected deaths predicted using over-dispersed Poisson model that accounts for temporal trends and seasonal and natural variability. Age standardised within each age group. Data: Short-term Mortality Fluctuations data series of Human Mortality Database 
Comparison of estimated excess deaths and reported covid-19 deaths

In most countries, the estimated number of excess deaths exceeded the number of reported deaths from covid-19 (table 2). For example, in both the US and the UK (that is, England, Wales, Northern Ireland, and Scotland combined), the estimated excess deaths were more than 30\% higher than the number of reported covid-19 deaths, and they were more than $50 \%$ higher in some other countries, including Spain, Poland, Hungary, Greece, Lithuania, Slovakia, Estonia, and South Korea. However, New Zealand, Norway, Denmark, Israel, France, Germany, Belgium, and Switzerland had a higher number of reported covid-19 deaths than estimated excess deaths.

\section{Annual mortality 2016-20}

The impact of the pandemic on trends in annual mortality rates for men and women in 2016-20 for each country is shown in supplementary figure S3. Men had consistently higher age standardised mortality rates than women across the period in all the countries. In general, age standardised mortality rates declined from 2016 to 2019, in both men and women. Whereas Denmark, Finland, South Korea, Norway, and New Zealand continued to show reduced mortality rates in 2020, most other countries experienced a marked increase in rates in both men and women, together with a widening of the gaps in mortality rates between the sexes. Sex specific annual mortality rates are shown for age groups 0-14, 15-64, 65-74, 75-84, and $\geq 85$ years in supplementary figure S4 (A-E).

\section{Model fit}

Supplementary figure S5 (A-B) shows the weekly percentage deviation from model predicted excess deaths in 2016-20, along with the 95\% confidence intervals, separately for males and females. It shows that the relative excess deaths fluctuated around zero between 2016 and 2019 in most countries indicating goodness of fit with a median of the median absolute deviation of 0.059 (interquartile range 0.042-0.068) (detailed country specific estimates, separately in males and females, are provided in supplementary table S4). However, some periods of moderate increase in excess mortality occurred during some winter months in some countries, consistent with known periods of excess mortality from seasonal influenza. We excluded these periods from the time periods used to estimate the counterfactual expected mortality (list of country specific dates excluded is available in supplementary table S2).

\section{Discussion}

In this international comparative study of excess deaths in relation to the covid-19 pandemic in 29 high income countries, all countries had excess deaths in 2020, except New Zealand, Norway, and Denmark. The highest excess deaths were in the US, Italy, England and Wales, Spain, and Poland. The highest excess death rates in men were in Lithuania, Poland, Spain,
Hungary, and Italy; the highest rates in women were in Lithuania, Spain, Hungary, Slovenia, and Belgium. Total deaths were below the expected level in New Zealand. Even though little sex difference existed in terms of total number or crude excess death rates, the age standardised excess death rate was noticeably higher in men than in women in most countries except New Zealand, Denmark, South Korea, Greece, Norway, Finland, Estonia, Northern Ireland, and Latvia. Most of the countries had underreporting of deaths from covid-19, an increase in non-covid-19 deaths, or a combination of both. On the other hand, the estimated number of excess deaths was lower than the reported covid-19 deaths in some countries (for example, Israel, France, Germany) owing to a reduction in non-covid-19 deaths in specific subgroups of the population (see supplementary methods for more details). Despite a recent trend of declining annual mortality rate between 2016 and 2019, the annual mortality rate increased substantially in 2020 in most of the countries, in both men and women. A similar trend was observed in sex differences in annual age standardised mortality rates.

\section{Comparison with previous literature}

Several previous studies have reported country specific excess deaths for the first few months of 2020. ${ }^{18192133-36}$ Mortality in younger age groups was reported to be at or lower than expected levels, which is consistent with our findings. ${ }^{1920}$ Estimated excess deaths in the US are consistent with the projections of more than 400000 excess deaths and recent estimates produced by the US Centers for Disease Control and Prevention (CDC). ${ }^{1837}$ Drawing on data up to May 2020, previous research reported that Italy, Spain, and England and Wales had the highest number of excess deaths, which is consistent with our findings. ${ }^{21} 38$ An estimated 47243 excess deaths were reported in England and Wales up to May 2020, ${ }^{33}$ and 2400-4000 excess deaths were estimated to have occurred in Portugal up to April 2020. ${ }^{34}$ The estimated number of excess deaths in England (excluding Wales) was 69925 between 21 March and 25 December according to Public Health England (PHE). ${ }^{19}$ Although not directly comparable (our estimates include aggregate data from England and Wales), our estimate of excess deaths is likely higher than the estimates from PHE. This could largely be due to different methods of estimation of the counterfactual expected counts and the varying time periods used. The PHE model, like most of the models estimating excess deaths, used the average of the past few years' data without considering the natural and seasonal variabilities in mortality pattern over the control period. Our estimate of excess deaths in Poland is noticeably higher than previously reported, which could also be attributed to a marked increase in mortality in October-December 2020. ${ }^{21}$ Recent reports, however, noted that in 2020 Poland recorded the highest number of deaths since the second world war. ${ }^{39}$ New Zealand was reported to have deaths at or below expected levels, which is consistent with our findings. ${ }^{2140}$ Our estimates show that Sweden had the 

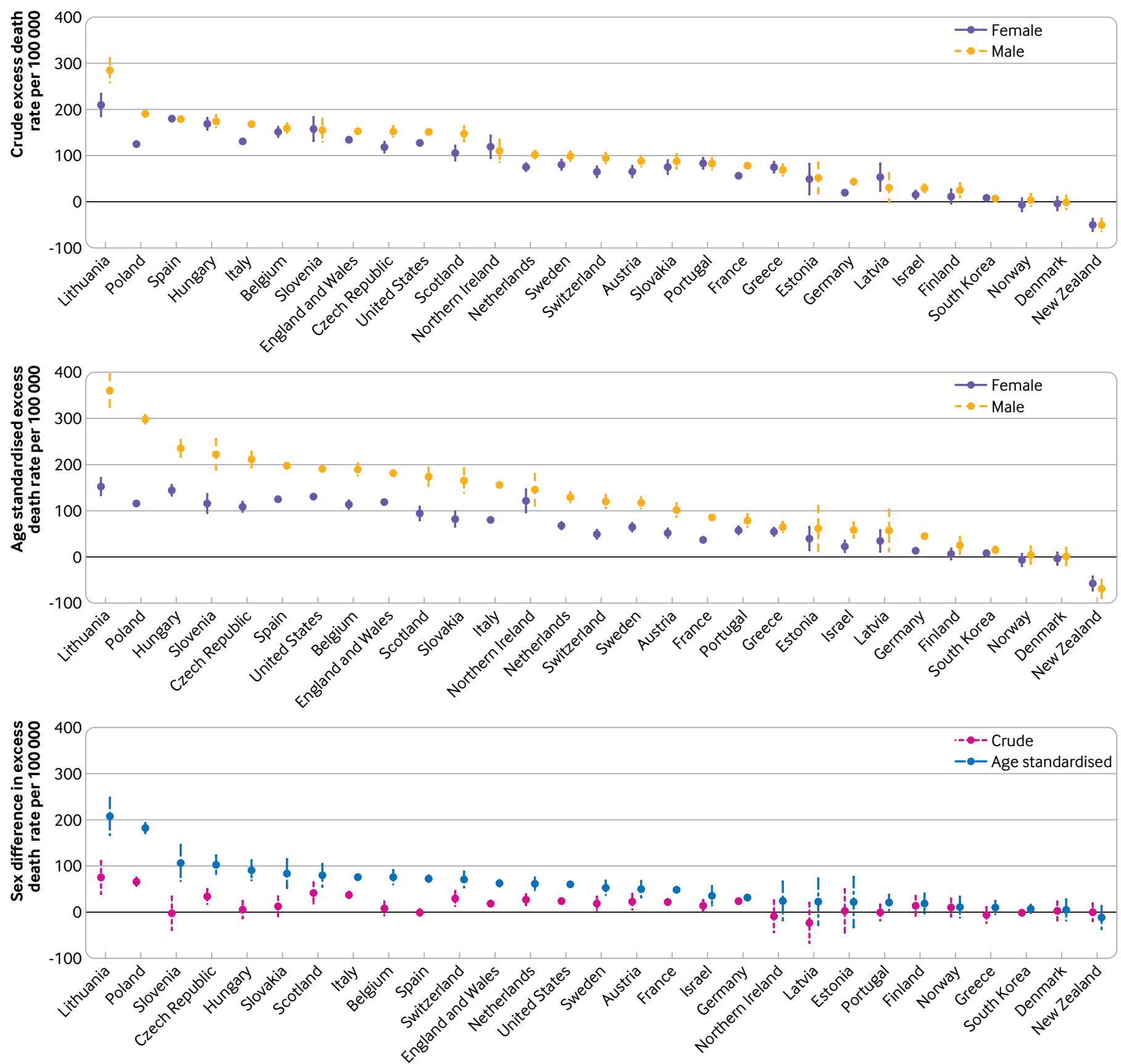

Fig 4 | Crude and age standardised excess death rates in 29 high income countries in 2020, by sex. Excess death rate (per 100000 ) in 2020 was calculated as difference in observed deaths and expected deaths predicted using over-dispersed Poisson model that accounts for temporal trends and seasonal and natural variability. Age standardised, where indicated, to 2013 European standard population. Bottom panel: estimates above horizontal line at zero indicate higher excess death rate in men. Data: Short-term Mortality Fluctuations data series of Human Mortality Database

highest excess deaths among the Nordic countries, which is also consistent with a previous report. ${ }^{41}$ Our estimated number of excess deaths in South Korea is lower than those reported by Statistics Korea. ${ }^{42} 43$ This is because these reports compared the mortality in 2020 with that in 2019, whereas our model examined the difference in 2020 compared with the expected mortality based on 2016-19 data.

Previous studies reported a disproportionately higher toll of covid-19 mortality in men, ${ }^{44-46}$ but our detailed analysis showed that this could vary from no difference to a substantial difference across the 29 countries. A previous study concluded that no sex difference existed in terms of excess deaths. ${ }^{21} \mathrm{By}$ contrast, our analysis shows that many countries with no sex difference in terms of crude excess death rate did show a remarkable sex difference after standardisation for age. However, we observed no sex difference in New Zealand, Denmark, South Korea, Greece, Norway, Finland, Estonia, Northern Ireland, or Latvia, even after age standardisation. ${ }^{21}$ Among the Nordic countries, Sweden showed the largest gaps 


\begin{tabular}{|c|c|c|c|c|}
\hline Country & $\begin{array}{l}\text { Total covid }-19 \text { deaths } \\
\text { reported* }(A)\end{array}$ & $\begin{array}{l}\text { Total excess deaths esti- } \\
\text { matedt (B) }\end{array}$ & $\begin{array}{l}\text { Difference between excess deaths and } \\
\text { reported covid-19 deaths (B-A) }\end{array}$ & $\begin{array}{l}\text { Ratio of excess deaths to reported cov- } \\
\text { id-19 deaths, } \%(B / A \times 100)\end{array}$ \\
\hline United States & 339014 & 458000 & 118986 & 135 \\
\hline United Kingdom‡ & 70860 & 94400 & 23540 & 133 \\
\hline Italy & 71925 & 89100 & 17175 & 124 \\
\hline Spain & 49824 & 84100 & 34276 & 169 \\
\hline Poland & 27118 & 60100 & 32982 & 222 \\
\hline France & 62867 & 43500 & -19367 & 69 \\
\hline Germany & 30297 & 25900 & -4397 & 85 \\
\hline Belgium & 19200 & 17900 & -1300 & 93 \\
\hline Hungary & 9047 & 16600 & 7553 & 183 \\
\hline Netherlands & 11090 & 15300 & 4210 & 138 \\
\hline Czech Republic & 11044 & 14400 & 3356 & 130 \\
\hline Sweden & 8279 & 9300 & 1021 & 112 \\
\hline Portugal & 6619 & 8500 & 1881 & 128 \\
\hline Greece & 4606 & 7700 & 3094 & 167 \\
\hline Switzerland & 7210 & 6800 & -410 & 94 \\
\hline Austria & 5881 & 6800 & 919 & 116 \\
\hline Lithuania & 1613 & 6800 & 5187 & 422 \\
\hline Slovakia & 1773 & 4400 & 2627 & 248 \\
\hline South Korea & 819 & 4000 & 3181 & 488 \\
\hline Slovenia & 2565 & 3200 & 635 & 125 \\
\hline Israel & 3226 & 2000 & -1226 & 62 \\
\hline Finland & 524 & 1000 & 476 & 191 \\
\hline Latvia & 559 & 820 & 261 & 147 \\
\hline Estonia & 204 & 670 & 466 & 328 \\
\hline Norway & 421 & -70 & NA & NA \\
\hline Denmark & 1174 & -160 & NA & NA \\
\hline New Zealand & 25 & -2500 & NA & NA \\
\hline \multicolumn{5}{|c|}{$\begin{array}{l}\text { NA=not applicable. } \\
\text { *Reported covid-19 deaths in } 2020 \text { (up to } 27 \text { December } 2020 \text {, end of } 52 \text { nd week). Source: Unified covid-19 dataset maintained by Johns Hopkins University Center for Systems Science and } \\
\text { Engineering (https://raw.githubusercontent.com/datasets/covid-19/main/data/countries-aggregated.csv). } \\
\text { †Total excess deaths estimated from model. Numbers }<1000 \text { are rounded to nearest ten; numbers between } 1000 \text { and }<100000 \text { are rounded to nearest hundred, and numbers } \geq 100000 \text { are } \\
\text { rounded to nearest thousand. } \\
\text { fTotal number of excess deaths in England and Wales, Scotland, and Northern Ireland. See supplementary methods for simpler explanation of discrepancies between reported covid-19 deaths } \\
\text { and estimated excess deaths. }\end{array}$} \\
\hline
\end{tabular}

in terms of sex inequality in age standardised excess death rate, with a much higher mortality rate in men than in women. This may be a result of a multitude of factors, including occupational and lifestyle factors between the sexes that may increase the likelihood of exposure to SARS-CoV-2 among men than women or differences in underlying comorbidities between men and women that might have increased the likelihood of death following infection..$^{45}$ 47-49 Many of these countries rank very high on the gender equality index, but no clear relation existed between gender equality and differences in age standardised excess death rate between men and women, with some countries that rank highly on gender equality indices having large differences between sexes and vice versa. ${ }^{50} 51 \mathrm{New}$ Zealand managed to keep deaths below the expected level in all the age groups in both men and women, with a corresponding narrowing of the gender inequality. The success in managing the covid-19 pandemic in New Zealand and South Korea to date may be attributed to their early viral elimination policies..$^{52-54}$

Previous studies in the US reported that about two thirds of the estimated excess deaths were reported as deaths from covid- $19,{ }^{55}$ which is lower than our estimate of $74 \%$ in the US. This may be indicative of a better reporting of, or an increase in, covid-19 deaths, or a combination of both, later in the pandemic.
Our study found that the existing sex inequality in annual standardised mortality rate, with higher rates in men than in women, was further widened in most of the countries during the first calendar year of the covid-19 pandemic. A large body of research reported that past pandemics have also widened existing disparities. ${ }^{56-59} \mathrm{~A}$ reduction in mortality (avoided mortality) was seen in children $<15$ years in some countries in 2020, which could be associated with a reduction in unintentional injuries (including drowning and car accidents) and a lower burden of cardiovascular and respiratory diseases potentially associated with a change in lifestyle or environmental factors during the periods of lockdown. ${ }^{60-63}$ However, long term data on the cause of deaths will be needed to fully examine the effects, because lockdown may have had other unintended consequences (for example, worsening mental health), which may take a longer time to affect overall mortality. ${ }^{13}$

In contrast to other countries, the excess death rates in women aged $\geq 85$ years in the US were higher than in their male counterparts. The exact reasons for such a discrepancy will require detailed exploration of the cause of deaths in this age group, but we propose some potential reasons. Firstly, according to the CDC's recent estimates of cause of deaths by age and sex, this is the only age group in which women had higher 
death rates than men across the causes of death in 2020-namely, covid-19 deaths (70985 v 50801), total deaths (616124v 393995), pneumonia deaths (54521 v 46828), pneumonia and covid-19 deaths (25989 v 23 086), influenza deaths (1065 v 734), and pneumonia, influenza, or covid-19 deaths (100473 $v 75$ 178). ${ }^{64}$ Secondly, covid-19 deaths in US nursing homes have been described as catastrophic with $>40 \%$ share of covid-19 deaths among this population that is only $0.6 \%$ of the total US population. ${ }^{65-67}$ Moreover, all cause mortality in US nursing homes had been decreasing until $2017 .^{68}$ With the decreasing trend, the expected all cause mortality in 2020 would be lower than the 2017 estimates of 534714 deaths. ${ }^{68}$ However, contrary to the expectations, the all cause mortality increased to 585429 in 2020, with the highest number of deaths occurring in the $\geq 85$ age group ( $\mathrm{n}=328387) .{ }^{69}$ Thirdly, 59\% of nursing home residents are women, ${ }^{70}$ and elderly female nursing home residents have a higher burden of obesity (36.1\% $v 31.8 \%)$ and hypertension (86\% $v$ 81.5\%) than their male counterparts. ${ }^{71}$ Fourthly, as depicted in supplementary figure S4 (E), although all cause mortality rates in men $\geq 85$ remained very similar to those in the past few years, the death rates in women $\geq 85$ years decreased sharply in 2019, but the increase in the death rate in 2020 was much steeper in women than in men. All these factors may have contributed to a higher estimated excess death rate in women than men in the $\geq 85$ year age category in the US.

\section{Strengths and limitations of study}

In this large international comparative study, we examined excess deaths associated with the covid-19 pandemic in 2020 by using detailed age and sex specific mortality data with robust and validated analytical methods. Methods for estimating excess deaths have varied substantially. The most commonly used method is to compare deviations in mortality with the average of the preceding few years. ${ }^{20}$ Comparing the deaths in the timeline of interest with the simple average of the previous few years ignores critical factors such as recent general health improvement and decline in mortality with time, seasonal and natural variability, and demographic changes. ${ }^{23} 24$ More nuanced methods of outbreak detection modelling have been proposed to detect aberrations in mortality on the basis of historical trends. ${ }^{72-74}$ These methods provide a point estimate and an upper bound for expected deaths and produce a conservative estimate of excess deaths by considering counts above these thresholds. ${ }^{18}$ More recently, Rizzi and Vaupel proposed a method to "shortcast" (neologism for short term forecasting) the average number of deaths in the absence of an event that relies exclusively on death counts. $^{24}$ Their approach is appealing owing to its simplicity but was applied to only four countries, and, as the authors specifically noted, this method is designed for short term forecasting. Therefore, this method may not be suitable for the covid-19 pandemic, which continues to exist more than a year after its emergence. Moreover, this method does not account for changing demographic composition. Karlinsky and Kobak take a much more traditional route to assessing excess mortality. ${ }^{75}$ For each country, they fit a linear regression with a slope for year and week specific coefficients without taking into account the possible changes in the population. To calculate counterfactual counts, they simply predict fitted values for 2020 . Their model relies on marginal death counts without stratification by age or sex, and hence is limited to exploring the differences by two of the most important predictors of mortality. Our dataset is richer than that used by the groups described above because it provides more granular data by age and sex in a large number of countries. Furthermore, our statistical model does not have the aforementioned limitations. We accounted for changes in the demographic profile of all countries by using age and sex specific population estimates.

A unique strength of the database is the use of the authoritative national agencies for data collection, extensive checks and data validation procedures, comparability across countries and time, highly detailed and uniform data formats, and availability of data on survival to the highest ages. However, we were limited to an analysis of countries that reported weekly deaths by age and sex for the entire study period of 2016-20. We acknowledge that no consensus exists in the literature on the historical time period for the estimation of the counterfactual expected deaths. We were also limited by the completeness of the data (for example, Canada and Australia have not yet reported complete data in 2020).

As highlighted previously, the variability around the estimated excess death in children $<15$ years is larger than in other age groups owing to sparse data. ${ }^{24}$ To make the analysis comparable, we presented our findings by five broader age groups. The 15-64 years age group represents the working age group, but it also consists of heterogeneous age groups in terms of risk of mortality. In an exploratory analysis, the rate of excess deaths was smaller in age groups $<45$ years but varied markedly in age groups 45-54 and 55-64 years (supplementary figure S6). Excess risk was also relatively low in females across all age groups (except in Hungary, where the rate was higher in women aged 55-64 years). Belgium, the Czech Republic, Hungary, Poland, and Scotland had the highest excess death rates in men aged 55-64 years (exceeding 100 excess deaths per 100000). The aggregated analysis essentially masks these nuanced trends in mortality rates.

We did not have the data to examine the variability in excess deaths by other potentially critical factors such as ethnicity and socioeconomic status. ${ }^{45} 59$ 76-81 We also did not examine within country regional differences in mortality owing to unavailability of such granular data. Even though we assumed a fairly stable population during 2020 within each country, some in-country migration or displacement could occur as a result of changes in job or financial situations. Although this assumption will more likely hold true for 
most countries, an underestimation of such population displacement may have resulted in an underestimation of excess deaths. ${ }^{23}$ Our analysis is restricted to the end of 2020 to make our estimates by calendar year comparable to the conventional mortality statistics reported by international agencies including the World Health Organization and the United Nations. Therefore, our study does not reflect the excess deaths experienced by some countries in early 2021. The indirect effects of a pandemic and its associated policy measures are multifactorial. ${ }^{13}$ Many of these may need a longer timeframe to have a measurable effect on mortality. Our analysis was unable to measure these effects. Also, we did not have access to individual patient level data to explore the cause of deaths, which would provide important insights about the sources and potential mechanisms of the direct and indirect effects of the pandemic and its associated policy measures. ${ }^{13}$ Although no visible mortality displacement occurred in our study, mortality displacement in one group may be masked by the ongoing excess mortality in other population groups. More studies with longer follow-up data are needed to disentangle this phenomenon.

\section{Policy implications and future directions}

Our study adds important insights on the direct and indirect effects of the covid-19 pandemic on total mortality. It underscores the importance of availability of age and sex disaggregated data for more nuanced analysis and estimation of the direct and indirect effect of the pandemic. A lack of detailed data from lower and middle income countries, especially those in Asia and Africa, calls for a globally coordinated effort to improve the local capacity in collecting and reporting critical vital statistics data promptly to aid evidence based healthcare policy decisions. New Zealand stood out as the only country that had a lower than expected mortality across all the age groups, in both men and women, with no sex difference in excess death rates, which could potentially be attributed to the country's elimination strategy early in the pandemic. ${ }^{52}{ }^{53}$ Our findings also suggest that many countries had an underestimation or underreporting of covid-19 deaths, a substantial increase in non-covid-19 deaths, or both. Reliable and timely monitoring of excess deaths would help to inform public health policy in investigating the sources of excess mortality in populations and would help to detect important social inequalities in the impact of the pandemic to inform more targeted interventions. ${ }^{82}$

Our study also highlights the need for nuanced analysis taking into account the other potential sources of social inequalities including ethnicity and socioeconomic status. This study provides a detailed and robust assessment of the impact of the covid-19 pandemic on total mortality up to the point that mass vaccination programmes started to become widely available throughout these countries. Future work will be needed to understand the impact of national vaccination programmes on mortality in 2021.

\section{AUTHOR AFFILIATIONS}

${ }^{1}$ Clinical Trial Service Unit and Epidemiological Studies Unit (CTSU), Nuffield Department of Population Health, University of Oxford, Oxford, UK

${ }^{2}$ MRC Epidemiology Unit, University of Cambridge, Cambridge, UK ${ }^{3}$ Max Planck Institute for Demographic Research, Rostock, Germany ${ }^{4}$ International Laboratory for Population and Health, National Research University Higher School of Economics, Moscow, Russian Federation

${ }^{5}$ Department of Biostatistics, Harvard T H Chan School of Public, Harvard University, Boston, MA, USA

${ }^{6}$ Department of Social and Behavioral Sciences, Harvard T H Chan School of Public Health, Harvard University, Boston, MA, USA

${ }^{7}$ Department of Data Science, Dana-Farber Cancer Institute, Boston, MA, USA

${ }^{8}$ Department of Pathophysiology and Transplantation, Università degli Studi di Milano, Milan, Italy

${ }^{9}$ Diabetes Research Centre, University of Leicester, Leicester, UK

${ }^{10} \mathrm{NIHR}$ Applied Research Collaboration-East Midlands, Leicester General Hospital, Leicester, UK

${ }^{11}$ NIHR Leicester Biomedical Research Centre, University Hospitals of Leicester NHS Trust and University of Leicester, Leicester, UK

${ }^{12}$ MRC Population Heath Research Unit, Nuffield Department of Population Health, University of Oxford, Oxford, UK

Contributors: NI conceptualised the study, with the input from all the co-authors. BL, MW, SL, RAI, and VMS supervised various aspects of the study. MW, SL, and BL are the co-senior authors. NI, IKlimkin, RJA, and DAJ did the statistical analysis, with inputs and supervision from VMS and RAI. VMS, JDA, and IKlimkin did the age standardisation of the excess deaths using their MPIDR method. NI wrote the first draft of the manuscript, and all the authors provided critical scholarly feedback. All the co-authors approved of the final version of the manuscript. The corresponding author attests that all listed authors meet authorship criteria and that no others meeting the criteria have been omitted. $\mathrm{NI}$ is the guarantor.

Funding: No specific funding was received for this study.NI receives salary support from the Nuffield Department of Population Health (NDPH), University of Oxford. BL acknowledges support from UK Biobank, the NIHR Oxford Biomedical Research Centre, and the BHF Centre of Research Excellence, Oxford. MW is supported by the Centre for Diet and Activity Research (CEDAR), a UK Clinical Research Collaboration (UKCRC) Public Health Research Centre of Excellence Funding from the British Heart Foundation, Cancer Research UK, Economic and Social Research Council, Medical Research Council (MRC), National Institute for Health Research (NIHR), and Wellcome Trust, under the auspices of the UKCRC. MW is also supported by the MRC (grant Nos MC_UU_12015/6 and MC_UU_00006/7). IKlimkin was fully supported, and VMS and JDA were partially supported, by the Basic Research Program of the National Research University Higher School of Economics. RAI and RJA are supported by the National Institutes of Health (R35GM131802 and T32ES007142, respectively). KK and TY are supported by the NIHR Applied Research Collaboration East Midlands (ARC EM) and the NIHR Leicester Biomedical Research Centre (BRC). Covid-19 research by TY is supported by the NIHR Leicester BRC and grants from the UKRI (MRC)-DHSC (NIHR) COVID-19 Rapid Response Rolling Call (MR/ V020536/1) and from HDR-UK (HDRUK2020.138). The BMJ open access fee was supported by research funding from the US Centers for Disease Control and Prevention Foundation (with support from Amgen). Employers/sponsors had no role in the design, analysis, or dissemination of the study. The views expressed in this article are those of the authors and not necessarily those of the entities the authors are affiliated with and/or supported by.

Competing interests: All authors have completed the ICMJE uniform disclosure form at www.icmje.org/coi_disclosure.pdf and declare: no specific funding was received for this study; the BMJ open access fee was supported by research funding from the US Centers for Disease Control and Prevention Foundation (with support from Amgen); $\mathrm{SL}$ reports grants from the MRC and research funding from the US Centers for Disease Control and Prevention Foundation (with support from Amgen); MW reports research funding from the British Heart Foundation, Cancer Research UK, Economic and Social Research Council, MRC, NIHR, and Wellcome Trust unrelated to this study; NI, SL, and VMS are members of the WHO-UN DESA Technical Advisory Group on covid-19 mortality assessment; KK is a member of the UK Scientific Advisory Group for Emergency (SAGE) and Independent SAGE; no 
other relationships or activities that could appear to have influenced the submitted work.

Ethical approval: As all the data were anonymous, and aggregated without any personal information, ethics approval was deemed waived.

Data sharing: All the data used in this study are publicly available and properly cited. However, more guided instruction to get access to the data for transparency and reproducibility will be provided on request.

The lead author affirms that the manuscript is an honest, accurate, and transparent account of the study being reported; that no important aspects of the study have been omitted; and that any discrepancies from the study as planned (and, if relevant, registered) have been explained.

Dissemination to participants and related patient and public communities: We will widely disseminate the main findings to members of the public through official (press release, institutional websites, and repositories), personal, and social media. We also plan to write a BMJ Opinion article to describe it in more general terms for the members of the public

Provenance and peer review: Not commissioned; externally peer reviewed.

This is an Open Access article distributed in accordance with the Creative Commons Attribution Non Commercial (CC BY-NC 4.0) license, which permits others to distribute, remix, adapt, build upon this work non-commercially, and license their derivative works on different terms, provided the original work is properly cited and the use is noncommercial. See: http://creativecommons.org/licenses/by-nc/4.0/.

1 Remuzzi A, Remuzzi G. COVID-19 and Italy: what next?Lancet 2020;395:1225-8. doi:10.1016/S01406736(20)30627-9

2 Ing EB, Xu QA, Salimi A, Torun N. Physician deaths from corona virus (COVID-19) disease. Occup Med (Lond) 2020;70:370-4 doi:10.1093/occmed/kqaa088

3 Islam N, Sharp SJ, Chowell G, et al. Physical distancing interventions and incidence of coronavirus disease 2019: natural experiment in 149 countries. BMJ 2020;370:m2743. doi:10.1136/bmj.m2743

4 Legido-Quigley H, Asgari N, Teo YY, et al. Are highperforming health systems resilient against the COVID-19 epidemic?Lancet 2020;395:848-50. doi:10.1016/S0140 6736(20)30551-1

5 Ranney ML, Griffeth V, Jha AK. Critical Supply Shortages - The Need for Ventilators and Personal Protective Equipment during the Covid-19 Pandemic. N Engl J Med 2020;382:e41. doi:10.1056/ NEJMp2006141

6 Leung CC, Lam TH, Cheng KK. Mass masking in the COVID-19 epidemic: people need guidance. Lancet 2020;395:945 doi:10.1016/S0140-6736(20)30520-1

7 Chu DK, Akl EA, Duda S, Solo K, Yaacoub S, Schünemann HJ COVID-19 Systematic Urgent Review Group Effort (SURGE) study authors. Physical distancing, face masks, and eye protection to prevent person-to-person transmission of SARS-CoV-2 and COVID-19: a systematic review and meta-analysis. Lancet 2020;395:1973-87. doi:10.1016/S0140-6736(20)31142-9

8 Han E, Tan MMJ, Turk E, et al. Lessons learnt from easing COVID-19 restrictions: an analysis of countries and regions in Asia Pacific and Europe. Lancet 2020;396:1525-34. doi:10.1016/S01406736(20)32007-9

9 Mafham MM, Spata E, Goldacre R, et al. COVID-19 pandemic and admission rates for and management of acute coronary syndromes in England. Lancet 2020;396:381-9. doi:10.1016/S01406736(20)31356-8

10 Morris EJA, Goldacre R, Spata E, et al. Impact of the COVID-19 pandemic on the detection and management of colorectal cancer in England: a population-based study. Lancet Gastroenterol Hepatol 2021;6:199-208. doi:10.1016/S2468-1253(21)00005-4

11 Mansfield KE, Mathur R, Tazare J, et al. Indirect acute effects of the COVID-19 pandemic on physical and mental health in the UK: a population-based study. Lancet Digit Health 2021;3:e217-30 doi:10.1016/S2589-7500(21)00017-0

12 Ball S, Banerjee A, Berry C, et al, CVD-COVID-UK Consortium. Monitoring indirect impact of COVID-19 pandemic on services for cardiovascular diseases in the UK. Heart 2020;106:1890-7. doi:10.1136/heartjnl-2020-317870

13 Beaney T, Clarke JM, Jain V, et al. Excess mortality: the gold standard in measuring the impact of COVID-19 worldwide?/ $R$ Soc Med 2020;113:329-34. doi:10.1177/0141076820956802

14 Godderis L, Luyten J. Challenges and opportunities for occupational health and safety after the COVID-19 lockdowns. Occup Environ Med 2020;77:511-2. doi:10.1136/oemed-2020-106645
15 Qureshi Al, Huang W, Khan S, et al. Mandated societal lockdown and road traffic accidents. Accid Anal Prev 2020;146:105747. doi:10.1016/j.aap.2020.105747

16 Holmes EA, O'Connor RC, Perry VH, et al. Multidisciplinary research priorities for the COVID-19 pandemic: a call for action for mental health science. Lancet Psychiatry 2020;7:547-60 doi:10.1016/ S2215-0366(20)30168-1

17 Galea S, Merchant RM, Lurie N. The Mental Health Consequences of COVID-19 and Physical Distancing: The Need for Prevention and Early Intervention. JAMA Intern Med 2020;180:817-8. doi:10.1001/ jamainternmed.2020.1562

18 National Center for Health Statistics. Excess Deaths Associated with COVID-19. 2021. https://www.cdc.gov/nchs/nvss/vsrr/covid19/ excess_deaths.htm.

19 Public Health England. Excess mortality in England, week ending 25 December 2020. https://fingertips.phe.org.uk/static-reports/ mortality-surveillance/excess-mortality-in-england-week-ending-25Dec-2020.html.

20 Office for National Statistics. Deaths registered weekly in England and Wales, provisional. https:// www.ons.gov.uk/peoplepopulationandcommunity/ birthsdeathsandmarriages/deaths/datasets/ weeklyprovisionalfiguresondeathsregisteredinenglandandwales.

21 Kontis V, Bennett JE, Rashid T, et al. Magnitude, demographics and dynamics of the effect of the first wave of the COVID-19 pandemic on all-cause mortality in 21 industrialized countries. Nat Med 2020;26:1919-28. doi:10.1038/s41591-020-1112-0

22 Kunst AE, Looman CWN, Mackenbach JP. Outdoor air temperature and mortality in The Netherlands: a time-series analysis. Am J Epidemiol 1993;137:331-41. doi:10.1093/oxfordjournals.aje. a116680

23 Acosta RJ, Irizarry RA. Monitoring Health Systems by Estimating Excess Mortality medRxiv [Preprint] 2020.

24 Rizzi S, Vaupel JW. Short-term forecasts of expected deaths. Proc Natl Acad Sci U S A 2021;118:e2025324118. doi:10.1073/ pnas.2025324118

25 Bhopal SS, Bhopal R. Sex differential in COVID-19 mortality varies markedly by age. Lancet 2020;396:532-3. doi:10.1016/S01406736(20)31748-7

26 Figliozzi S, Masci PG, Ahmadi N, et al. Predictors of adverse prognosis in COVID-19: A systematic review and meta-analysis. Eur J Clin Invest 2020;50:e13362. doi:10.1111/eci.13362

27 Wilmoth JR, Andreev K, Jdanov D, et al. Methods protocol for the human mortality database. 2021. https://www.mortality.org/Public/ Docs/MethodsProtocol.pdf.

28 Barbieri M, Wilmoth JR, Shkolnikov VM, et al. Data Resource Profile: The Human Mortality Database (HMD). Int Epidemiol 2015;44:1549-56. doi:10.1093/ije/dyv105

29 Németh L, Jdanov DA, Shkolnikov VM. An open-sourced, webbased application to analyze weekly excess mortality based on the Short-term Mortality Fluctuations data series. PLoS One 2021;16:e0246663. doi:10.1371/journal.pone.0246663

30 Human Mortality Database. Short-Term Mortality Fluctuations Data series (STMF). 2020. https://www.mortality.org/Public/STMF_DOC/ STMFNote.pdf.

31 Publications Office of the EU. Revision of the European Standard Population: Report of Eurostat's task force: 2013 edition. 2013. https://data.europa.eu/doi/10.2785/11470.

32 Klimkin I, Shkolnikov V, Jdanov D. Calculation of week-specific agestandardized death rates from STMF data on mortality by broad age intervals. Max Planck Institute for Demographic Research, 2021 doi:10.4054/MPIDR-WP-2021-004

33 Kontopantelis E, Mamas MA, Deanfield I, Asaria M, Doran T. Excess mortality in England and Wales during the first wave of the COVID-19 pandemic. J Epidemiol Community Health 2021;75:213-23. doi:10.1136/jech-2020-214764

34 Stang A, Standl F, Kowall B, et al. Excess mortality due to COVID-19 in Germany. J Infect 2020;81:797-801. doi:10.1016/j. jinf.2020.09.012

35 Alicandro G, Remuzzi G, La Vecchia C. Italy's first wave of the COVID-19 pandemic has ended: no excess mortality in May, 2020 Lancet 2020;396:e27-8. doi:10.1016/S0140-6736(20)31865-1

36 Scortichini M, Schneider Dos Santos R, De' Donato F, et al. Excess mortality during the COVID-19 outbreak in Italy: a two-stage interrupted time-series analysis. Int J Epidemiol 2021;49:1909-17. doi:10.1093/ije/dyaa169

37 Bauchner H, Fontanarosa PB. Excess Deaths and the Great Pandemic of 2020. JAMA 2020;324:1504-5. doi:10.1001/jama.2020.20016

38 Duncan P, McIntyre N, Barr CU. UK's excess death toll since start of Covid pandemic passes 100,000 . 2021. https://www theguardian. com/world/2021/feb/02/uk-excess-death-toll-since-start-of-covidpandemic-passes-100000

39 Tilles D. Poland recorded more deaths in 2020 than any year since WWII. 2021. https://notesfrompoland.com/2021/01/04/polandrecorded-more-deaths-in-2020-than-any-year-since-wwii/. 
40 Kung S, Doppen M, Black M, Hills T, Kearns N. Reduced mortality in New Zealand during the COVID-19 pandemic. Lancet 2021;397:25. doi:10.1016/S0140-6736(20)32647-7

41 Diderichsen F. How did Sweden Fail the Pandemic?/nt J Health Serv 2021;002073142199484:20731421994848. doi:10.1177/0020731421994848

42 Statistics Korea. Preliminary Results of Birth and Death Statistics in 2020. Statistics Korea, 2021.

43 Lee E, Lee S, Sejersen T The Role of CRVS in Estimating COVID-19 related Excess Deaths in South Korea. In: Conflict E, Settings F, eds. Compendium of Good Practices: Harnessing Civil Registration and Vital Statistics (CRVS. Centre of Excellence for Civil Registration and Vital Statistics Systems, 2021

44 Peckham H, de Gruijter NM, Raine C, et al. Male sex identified by global COVID-19 meta-analysis as a risk factor for death and ITU admission. Nat Commun 2020;11:6317. doi:10.1038/s41467020-19741-6

45 Islam N, Khunti K, Dambha-Miller H, Kawachi I, Marmot M. COVID-19 mortality: a complex interplay of sex, gender and ethnicity. Eur Public Health 2020:30:847-8. doi:10.1093/eurpub/ckaa150

46 Bhopal R. Covid-19 worldwide: we need precise data by age group and sex urgently. BMJ 2020;369:m1366. doi:10.1136/bmj.m1366

47 Channappanavar R, Fett C, Mack M, Ten Eyck PP, Meyerholz DK, Perlman S. Sex-Based Differences in Susceptibility to Severe Acute Respiratory Syndrome Coronavirus Infection. J Immunol 2017:198:4046-53. doi:10.4049/jimmunol.1601896

48 Islam N, Lewington S, Kharbanda RK, Davies J, Várnai KA, Lacey B. Sixty-day consequences of COVID-19 in patients discharged from hospital: an electronic health records study. Eur J Public Health 2021;31:280-2. doi:10.1093/eurpub/ckab009

49 Yates T, Zaccardi F, Islam N, et al, ISARIC4C investigators. Obesity, ethnicity and risk of critical care, mechanical ventilation and mortality in patients admitted to hospital with COVID-19: Analysis of the ISARIC CCP-UK cohort. Obesity (Silver Spring) 2021. doi:10.1002/oby. 23178

50 World Economic Forum. Global gender gap report 2020 . World Economic Forum, 2019.

51 Kang J, Jang YY, Kim J, et al. South Korea's responses to stop the COVID-19 pandemic. Am J Infect Control 2020;48:1080-6. doi:10.1016/j.ajic.2020.06.003

52 Baker MG, Wilson N, Anglemyer A. Successful Elimination of Covid-19 Transmission in New Zealand. N Engl J Med 2020;383:e56. doi:10.1056/NEJMc2025203

53 Baker MG, Kvalsvig A, Verrall AJ. New Zealand's COVID-19 elimination strategy. Med J Aust 2020;213:198-200.e1. doi:10.5694/ mja2.50735

54 Baker MG, Wilson N, Blakely T. Elimination could be the optimal response strategy for covid-19 and other emerging pandemic diseases. BMJ 2020;371:m4907. doi:10.1136/bmj.m4907

55 Woolf SH, Chapman DA, Sabo RT, Weinberger DM, Hill L, Taylor DDH. Excess Deaths From COVID-19 and Other Causes, March-July 2020. JAMA 2020;324:1562-4. doi:10.1001/jama.2020.19545

56 Fanning PJ. Influenza and inequality: one town's tragic response to the great epidemic of 1918. University of Massachusetts Press, 2010.

57 Fry CV. 'Never Let a Good Crisis Go To Waste': The impact of the 2014 ebola epidemic on West African science. Massachusetts Institute of Technology, 2019.

58 Grantz KH, Rane MS, Salje H, Glass GE, Schachterle SE, Cummings DA. Disparities in influenza mortality and transmission related to sociodemographic factors within Chicago in the pandemic of 1918 Proc Natl Acad Sci U S A 2016;113:13839-44. doi:10.1073/ pnas. 1612838113

59 Islam N, Lacey B, Shabnam S, et al. Social inequality and the syndemic of chronic disease and COVID-19: county-level analysis in the USA. J Epidemiol Community Health 2021. doi:10.1136/jech2020-215626

60 Barone E. Fewer Children Died in 2020, Despite the Pandemic. Experts Are Trying to Figure Out Why. 2021. https://time. com/5929751/childhood-mortality-2020-covid-19/.

61 Centers for Disease Control and Prevention. Ten Leading Causes of Death and Injury. 2020. https://www.cdc.gov/injury/wisqars/ LeadingCauses_images.html.
62 Chen K, Wang M, Huang C, Kinney PL, Anastas PT. Air pollution reduction and mortality benefit during the COVID-19 outbreak in China. Lancet Planet Health 2020;4:e210-2. doi:10.1016/S2542 5196(20)30107-8

63 Son J-Y, Fong KC, Heo S, Kim H, Lim CC, Bell ML. Reductions in mortality resulting from reduced air pollution levels due to COVID-19 mitigation measures. Sci Total Environ 2020;744:141012. doi:10.1016/j.scitotenv.2020.141012

64 Centers for Disease Control and Prevention. Provisional COVID-19 Death Counts by Sex, Age, and State. 2021. https://data.cdc.gov/ NCHS/Provisional-COVID-19-Death-Counts-by-Sex-Age-and-S/9bhghcku.

65 Roy A. The Most Important Coronavirus Statistic: 42\% Of U.S. Deaths Are From 0.6\% Of The Population. 2020. https://www.forbes.com/ sites/theapothecary/2020/05/26/nursing-homes-assisted-livingfacilities-0-6-of-the-u-s-population-43-of-u-s-covid-19-deaths/.

66 Prasad R. Coronavirus: How bad is the crisis in US care homes? 2020 https://www.bbc.com/news/world-us-canada-53172302.

67 Bondy H. 39\% of Covid-19 deaths have occurred in nursing homes - many could have been prevented: report. 2020. https://www. nbcnews.com/know-your-value/feature/39-covid-19-deaths-haveoccurred-nursing-homes-many-could-ncna1250374.

68 Cross SH, Warraich HJ. Changes in the Place of Death in the United States. N Engl J Med 2019;381:2369-70. doi:10.1056/ NEJMc1911892

69 Centers for Disease Control and Prevention. NVSS Provisional COVID-19 Deaths by Place of Death and Age. 2021. https://data. cdc.gov/NCHS/NVSS-Provisional-COVID-19-Deaths-by-Place-ofDeath/4va6-ph5s.

70 Gorges RJ, Konetzka RT. Factors Associated With Racial Differences in Deaths Among Nursing Home Residents With COVID-19 Infection in the US. JAMA Netw Open 2021;4:e2037431. doi:10.1001/ jamanetworkopen 2020.37431

71 National Center for Health Statistics. Health, United States, 2019 Hyattsville, MD. National Center for Health Statistics, 2021.

72 Farrington CP, Andrews NJ, Beale AD, et al. A Statistical Algorithm for the Early Detection of Outbreaks of Infectious Disease. I R Stat Soc SerA Stat Soc 1996;159:547-63. doi:10.2307/2983331

73 Höhle M, Paul M. Count data regression charts for the monitoring of surveillance time series. Comput Stat Data Anal 2008;52:4357-68. doi:10.1016/j.csda.2008.02.015

74 Noufaily A, Enki DG, Farrington P, Garthwaite P, Andrews N, Charlett A. An improved algorithm for outbreak detection in multiple surveillance systems. Stat Med 2013;32:1206-22. doi:10.1002/sim.5595

75 Karlinsky A, Kobak D. The World Mortality Dataset: Tracking excess mortality across countries during the COVID-19 pandemic.medRxiv [Preprint] 2021. doi:10.1101/2021.01.27.21250604

76 Rossen LM, Branum AM, Ahmad FB, Sutton P, Anderson RN. Excess Deaths Associated with COVID-19, by Age and Race and Ethnicity United States, January 26-October 3, 2020. MMWR Morb Mortal Wkly Rep 2020;69:1522-7. doi:10.15585/mmwr.mm6942e2

77 Platt L, Ross W. Are some ethnic groups more vulnerable to COVID-19 than others? Institute for Fiscal Studies, 2020.

78 Khunti K, Platt L, Routen A, Abbasi K. Covid-19 and ethnic minorities: an urgent agenda for overdue action. BMJ 2020;369:m2503. doi:10.1136/bmi.m2503

79 Nafilyan V, Islam N, Mathur R, et al. Ethnic differences in COVID-19 mortality during the first two waves of the Coronavirus Pandemic: a nationwide cohort study of 29 million adults in England medRxiv 2021:2021.02.03.21251004. doi:10.1101/2021.02.03.21251004

80 Nafilyan V, Islam N, Ayoubkhani D, et al. Ethnicity, household composition and COVID-19 mortality: a national linked data study. I $R$ Soc Med 2021;114:182-211. doi:10.1177/0141076821999973

81 Razieh C, Zaccardi F, Islam N, et al. Ethnic minorities and COVID-19: Examining whether excess risk is mediated through deprivation. Eur Public Health 2021;21:ckab041. doi:10.1093/eurpub/ckab041

82 Marmot M, Allen J, Goldblatt P, et al. Fair society, healthy lives. 2011.

\section{Web appendix: Supplementary materials}

